\title{
Quantifying the ice storage in the Upper Indus River basin with the ground-penetrating radar measurements and Glacier Bed Topography version 2 modeling
}

\author{
Xiaojuan Zou ${ }^{1}$, Haifeng $\mathrm{Gao}^{2}$, Yinsheng Zhang ${ }^{1}$, Ning $\mathrm{Ma}^{3}$, Suhaib Farhan ${ }^{4}$, and Jianfeng \\ $\mathrm{Wu}^{1}$ \\ ${ }^{1}$ Key Laboratory of Tibetan Environment Changes and Land Surface Processes \\ ${ }^{2}$ Satellite Environment Center \\ ${ }^{3}$ Key Laboratory of Water Cycle and Related Land Surface Processes \\ ${ }^{4}$ Pakistan Space \& Upper Atmosphere Research Commission
}

August 23, 2020

\begin{abstract}
Ice reserve estimates is a fundamental prerequisite for the water resources management, the upper Indus river basin (UIB) possesses the most abundant mid-latitude ice resources outside the poles. However, the ice reserve estimates remain unclear due to limited accessibility. We validated the critical parameters of the GlabTop2 model through ground-penetrating radar (GPR) measured ice thickness, compared the plots and profiles of the GPR-measured ice bed elevation versus GlabTop2estimated results, integrated with GlabTop, Volta model, and the inverse distance weighted (IDW) interpolated results on various sized glaciers, a reasonable parametric scheme $(\tau=120 \mathrm{kPa}$ and $\mathrm{f}=0.8)$ of GlabTop2 was selected to apply on vast amounts of glaciers in the UIB region. GlabTop2 estimates indicated that the ice thickness of the UIB was varying from 0 to $488.1 \mathrm{~m}$, with an average value of $74.4 \mathrm{~m}$. Significant spatial heterogeneity exists in the sub-basins, Shyok, Shigar, and Hunza high-altitude sub-catchments own the most abundant ice reserve, less quantity was stored in the Western Himalaya and Hindukush ranges, which accounts for a small proportion (11.3\% and 6.9\%, respectively). A total of $1269.7 \mathrm{~km} 3$ ice volume can be converted to $1142.7 \mathrm{~km} 3$ water resources, and it can supply at least $16.1 \mathrm{y}$ for the Besham hydrological station as runoff without considering the glacier process and other variables. The UIB relies on the glacier melting of the midstream because they are keeping in a self-sufficient state, in contrast, it will be up against water shortage in the future evenly, especially for the upper reaches and downstream area. Our estimates will provide the baseline information for water resources planning and management of the Indus river.
\end{abstract}

\section{KEYWORDS}

UIB, ice thickness, ice reserves, GPR, optimal parametric scheme, GlabTop2, IDW, water resources

\section{1 | INTRODUCTION}

With the combination of western disturbance (WDs), Indian summer monsoon (ISM), and Tibetan anticyclone principal synoptic systems, the climate pattern of the Hindukush-Karakoram-Western Himalaya (HKKH) mountain ranges are different from other adjacent Tibetan Plateau (TP) region, hence HKKH comprises the most heavily glacierized watershed outside the poles (Bishop et al., 2010; Farhan, Zhang, Ma, Guo \& Ma, 2015; Hewitt, 1998; Palazzi, Hardenberg \& Provenzale, 2013; Treydte et al., 2006). The Indus river emerges from the HKKH ranges, and the upper Indus basin (UIB) is known as "Pakistan Water 
Tower" (Farinotti, 2017; Immerzeel, Ludovicus \& Bierkens, 2010). Comprehensive analysis of the Water Tower Index indicated that UIB ranked top of the most critical and vulnerable unit in Asia even globally with abundant water resources (Immerzeel et al., 2019). More than $40 \%$ of freshwater in UIB depends on the seasonal ice/snow melting, it satisfies municipal and industrial water usage for more than 237 million people living in the downstream area. Global warming, along with the heavy irrigation and densely population are creating ever-greater pressure on exploiting mountain glacier resources, which makes the Indus aquifer the most overstressed aquifer worldwide (Lutz, Immerzeel, Shrestha \& Bierkens, 2014; Pritchard, 2019). Synthesizing knowledge of the ice reserves is becoming a fundamental prerequisite for the glacier runoff project for water resources allocation and socio-economic development (Cogley, 2012; Radić \& Hock, 2011; Vaughan et al., 2013). Most research was concentrated on glacier change, the precise ice reserves estimates in the UIB region remain unclear due to limited accessibility (Bolch et al., 2012; Khan, Naz \& Bowling, 2015).

Multiple approaches have been proposed for deducing ice reserves recently, including the geodetic surveying, semi-empirical formula, physical models, and other methods (Farinotti et al., 2019; 2017). Ice core drilling, gravimeter instrument, and ground-penetrating radar (GPR) technique can be classified as geodetic surveying, the high cost makes drilling technique just used for auxiliary medium to glacier structure although it is the most intuitive method with the highest precision (Garzonio et al., 2018); Gravimeter instrument was once tested on Batura glacier in northern Pakistan (BGIG, 1979); GPR technique is a radio-echo detection method that using electromagnetic wave to acquire ice thickness, its high-resolution accuracy and efficiency in noninvasive subsurface makes it is improving continually. During the past three decades, GPR has been applied in the inner and eastern TP widely (Gergan, Dobhal \& Kaushik, 1999; Ma et al., 2000; Marussi, 1964; Singh et al., 2012). The second category is the semi-empirical formula, $V$ - $A$ scaling constructs the correlation relationship by linear geostatistical regression, considering that the ice flow and surface landform remain stable, it is suitable for populations of glaciers (Radic \& Hock, 2013). The physical model can be sorted as the third category, which consists of shallow ice approximation (SIA), mass conserving, minimization, and velocity-based model. Glacier Bed Topography version 2 (GlabTop2) has been conducted widely for its operability, efficient, and theoretical reliability that originated from the classic laminar flow hypothesis (Linsbauer et al., 2016), it is developed from GlabTop and avoids the laborious process of drawing branch lines manually. Mass conserving, minimization, and velocity-based models were applied to the unique glacier through surface characteristics (Fürst et al., 2017; Maussion et al., 2019). Even the valley glacier fill thickness can be estimated using artificial neural networks that corresponding to the fourth category.

Numerous investigators have applied multiple methods to assess ice reserves in HKKH region, including $V$ - $A$ scaling law, slope-depth, HF-model, GlabTop2, GlabTop2_IITB, Open Global Glacier Model (OGGM) (Bahr, Pfeffer \& Kaser, 2015; Chen \& Ohmura, 1990; Farinotti et al., 2019; Huss \& Farinotti, 2012; Liu, Shen, Sun \& Li, 2002). The evaluated ice volume of the entire Karakoram-Western Himalaya region (KH) is $2.2-3.5 \times 10^{3} \mathrm{~km}^{3}$ with an ice area of $16.89 \times 10^{3} \mathrm{~km}^{2}$ approximately (Frey et al., 2014), it was calibrated by GPR-measured points on Baltoro and Chhota Shigri glaciers (Azam et al., 2012; Marussi, 1964). GPR work is the precious verification materials for ice reserves estimation, rare ice thickness and long-term glacial change measurements were involved in the South Asia West district (WGI Partition), in particular of the UIB region (Gärtner et al., 2014; Grinsted, 2013; Hewitt, 2016). Few mapping and further ground-based investigations were carried out before 1995 by the Batura Glacier Investigation Group (BGIG) (BGIG, 1979; Zhang, Chen \& Wang, 1996).

In light of the unique geographical and strategic position of the UIB region, the ancient Silk Road from China to South Asia and the modern Karakoram highway both pass through this kernel zone, research on ice reserves can protect against extreme water stress on seasonal and longer time scales, even to maintain social development and geopolitical stability. The main objectives of this paper are to (1) present GPRsurveyed ice thickness of typical glaciers in the UIB sub-basins; (2) compare the plots and profiles of the GPR-measured ice bed elevation versus GlabTop2-estimated results, integrated with GlabTop, Volta model, and the IDW interpolated results, then select the optimized parametric scheme of GlabTop2; (3) simulate the ice reserves of the entire UIB and its sub-catchments, and assess the potential hydrological effect of glacier resources. 


\section{2 | STUDY AREA}

As shown in Figure 1, the Indus river basin $\left(24^{\circ}-37^{\circ} \mathrm{N}, 66^{\circ}-82^{\circ} \mathrm{E}\right)$, located in the subtropical arid zone with semiarid climate, is a typical outflow basin. It covers $\sim 1.22 \times 10^{6} \mathrm{~km}^{2}$ of total area (Dahri et al., 2016; Immerzeel, Ludovicus \& Bierkens, 2010), and includes $\sim 1.72 \times 10^{5} \mathrm{~km}^{2}$ area lies upstream Tarbela dam situated at the Besham city of northern Pakistan, which is defined as the UIB $\left(31^{\circ}-37^{\circ} \mathrm{N}, 72^{\circ}-82^{\circ} \mathrm{E}\right)$ with the elevations ranging from 200 to $8600 \mathrm{~m}$, UIB has mean annual precipitation around $815 \mathrm{~mm}$, and an annual temperature is estimated between -10 and 22. An adopted watershed division scheme in this study was derived from SRTM DEM (90 m) (Khan, Richards, Parker, McRobie \& Mukhopadhyay, 2014), there is no definite boundary among the HKKH ranges. The UIB is generally divided into eight drainage units by river mainstream and its tributaries, Gilgit and UIB_Downstream (UIB_D) sub-watersheds draining the Hindukush range, the Karakoram range comprises Hunza, Shigar, and Shyok sub-watersheds, and the Western Himalaya range is composed of Astore, Kharmong, and Shiquanhe sub-watersheds. According to the latest research and Pakistan glacier inventory (PGI), 12\% part of the UIB area was glaciated, the cumulative area of 11,711 glaciers is $1.78 \times 10^{4} \mathrm{~km}^{2}$ approximately, and $70 \%$ of glaciers are distributed in high altitude sub-basins (i.e., Hunza, Shigar, and Shyok) (Bajracharya \& Basanta, 2011; SUPARCO \& ITPCAS, 2015).

FIGURE 1 Location of (a) the Indus river basin and (b) the UIB sub-basins

\section{3 | DATA AND METHODOLOGY}

\subsection{Data (Glacier inventory and digital elevation model)}

Spatial data included the digital elevation model (DEM) and PGI, SUPARCO released the available latest PGI database in cooperation with ITPCAS, previous studies rely on the old version of the glacier database mostly, therefore the accumulated glacier area was too large. PGI was originated from Landsat-8 (30 m) imagery that acquired from 2013 to 2015. The potential error in the glacial boundary estimated measurement $(E b)$, in case of the debris-covered is $2.6 \%$, whereas for the clean glacier area is $1.9 \%$, with the calculated adjustment error is below $0.35 \%$. Similarly, to assess the average error $(\vartheta)$, the PGI was compared with the boundaries delineated through some high-resolution multispectral images of Pleiades and SPOT-5, 6 \& 7. In total, 32 glaciers were randomly selected for this comparison, the result shows less than $9 \%$ difference in the debris-covered outlines, on the other hand, the $\vartheta$-value in clean glacier outline is found less than $5 \%$ (SUPARCO \& ITPCAS, 2015). We counted smaller glacier area because of the improved mapping accuracy, and PGI excluded glaciers with an area that less than $0.01 \mathrm{~km}^{2}$. Meanwhile, we used the Chinese Glacier Inventory version 2.0 (CGI2.0) (http://data.tpdc.ac.cn/) and GLIMS Randolph Glacier Inventory version 6.0 (RGI6.0) (http://www.glims.org/RGI/) as the supplemental database to determine glacier outline of a small part of Shyok and Kharmong sub-basins that PGI uncovered (Guo et al., 2015).

The quality of GlabTop2-modeled ice thickness largely depends on DEM, and we derived the topographic inputs from the free Shuttle Radar Topography Mission Digital Elevation Model (SRTM-C DEM) (http://dds.cr.usgs.gov/srtm/version2_1/SRTM1), which has a high spatial resolution of 1 arc-second (approximately $30 \mathrm{~m}$ ). SRTM-C DEM was released in 2011 by NASA and NGA and acquired using a radar interferometry technique. We can collect the most accurate glacier surface elevation because it can penetrate many meters into snow firm efficiently and has been used successfully over $80 \%$ of the earth's land surface between $60^{\circ} \mathrm{N}$ and $56^{\circ} \mathrm{S}$ latitude interval. In the subsequent study, we mosaiced the SRTM-C DEM, and projected it to Universal Transverse Mercator Projection (UTM43N) and World Geodetic System 1984 ellipsoidal elevation (WGS84), all GPS data were kept the unified projections. 


\section{2 | Methodology}

\subsection{1 | Ground-penetrating radar and GPS field investigation}

In the 1980s, the Lanzhou Institute of Glaciology and Geocryology, Chinese Academy of Science conducted the B-1 GPR work on the Antarctic Nelson, Urumqi glacier No. 1, and Hailuogou glacier (Su, Ding \& Liu, 1984; Zhang, Zhu, Qian, Chen \& Shen, 1985). A direct comparison between the GPR-surveyed ice depth with the results derived from the hot water drilling technique indicated that radar results were usually within $\pm 5 \%$ deviation (Liu, 2012), it was verified by the precise ice core drilling data down to the bedrock in the ablation area of the Hailuogou glacier, the B-1 GPR were quite satisfied with an error below $5 \mathrm{~m}$ (Wang, Li, Shen \& Huang, 1996). In this study, we used an impulse B-1 modified GPR system with a separate transmitter and receiver antenna separated by a fixed distance of 5 or $10 \mathrm{~m}$, the low frequency (approximately 2-220 MHz) is much more suitable for probing mountain glaciers, this GPR has a standard offset geometry with point measuring mode with a 5-MHz resistively loaded dipole antenna length of $10 \mathrm{~m}$ and wavelength of $33.8 \mathrm{~nm}$. On the two-dimensional radar graphic, we derived ice thickness $(h)$ from the vertical axis radar wave and calculated the two-way travel time by the following equation:

$h=\frac{\sqrt{v^{2} t^{2}-x^{2}}}{2}(1)$

where $t$ refers to the two-way travel time of radar wave, $x$ refers to the distance between transmitter and receiver antenna, and $v$ refers to the velocity of radar signal in the glacier. The speed of electromagnetic wave propagation in the ice was assessed to be $0.169-0.171 \mathrm{~m} \mathrm{~ns}^{-1}$, we set it to be $0.169 \pm 0.002 \mathrm{~m} \mathrm{~ns}^{-1}$, ensuring the relative error was within the accuracy demands of glaciology research.

During the actual operation process, firstly, we adjusted a start point of echo wave to check the whole wave shape was displayed on the GPR screen, then measured the $t$-value between the direct wave arrival through the air and the reflections from the ice bedrock, finally, we determined the $h$-value of measured points by identifying the ice and bedrock interface in the radar graphic. Glacier surface elevation of GPR points was surveyed simultaneously by a differential global positioning system (DGPS) device (SF-3050 GNSS, NavCom Technology, Inc., accuracy $<0.05 \mathrm{~m}$ ) and a portable GPS (Shtech, accuracy[?] +- $1 \mathrm{~m}$ ). The accuracy of ice thickness was decided by two factors: one is the measuring system, another is the property of ice and bedrock, the accuracy of travel time was determined to be $+-10 \mathrm{~ns}(1.6 \mathrm{~m})$ from the oscilloscope trace. In our study, Batura glacier, the maximum error was +- $2.4 \mathrm{~m}$ (the highest thickness measurement $201 \mathrm{~m}$ ), within the quoted error at $+-5 \%$.

\subsection{2 | Description of GlabTop2 Model}

GlabTop2 is a grid-based and slope-dependent ice thickness estimate model, Linsbauer et al. (2009) established and developed it based on the flow mechanics of the relationship between average basal shear stress $(\tau$ ) with shape factor $(f)$ (Nye, 1952; Paterson, 1970), the detailed formula explanation of GlabTop2 were depicted as follows:

$h=\frac{\tau}{\varphi \rho \gamma \sin (\alpha)}(2)$

$$
H \leq 1.6 \mathrm{~km}, \tau=0.005+1.598 H-0.435 H^{2}
$$

$H>1.6 \mathrm{~km}, \quad \tau=150 \mathrm{kPa}(3)$

$f=\frac{w}{h_{m}}(4)$

where the quantity of $\tau$ is under a perfect-plasticity assumption for the flow rheology. $\tau$ is parameterized with the glacier vertical elevation range $(\Delta H)$ (Haeberli \& Hölzle, 1995). The $f$-values depends on the aspect ratio of half-width $(w)$ to the midpoints' depth on central flowline $\left(h_{m}\right)$ along the glacier cross-section, it is usually set to 0.8 for all glaciers (Paterson, 1994). $\rho$ refers to the ice density $\left(900 \mathrm{~kg} \mathrm{~m}^{-3}\right), g$ refers to the gravitational acceleration $\left(9.81 \mathrm{~m} \mathrm{~s}^{-2}\right)$, and $a$ refers to the surface slope. A detailed working flow chart for 
processing data, GPR diagram, and GlabTop2 illustration schematic were presented in Figure 2. GlabTop2 calculated ice thickness for selection of a set of randomly picked DEM cells within the glacierized area, then interpolated to the entire mask, which was fully automated and required only glacier mask, DEM, and surface slope as inputs. It is indispensable for solving the problem of the non-measured area (Farinotti, 2017; Frey et al., 2014), and the prospect is considerable by using GPR-measured ice thickness to modify the GlabTop2 results.

FIGURE 2 (a) Working flow chart for processing data, (b) GPR (Liu, 2012), and (c) GlabTop2 illustration schematic (Frey et al., 2014)

\section{4 | Results and Discussions}

\section{1 | Ice Thickness Measurements}

We selected six typical glaciers of the UIB region to conduct GPR measurements, their geographical location and information was presented in Figure 3, they have different shapes and are suitable for GPR investigation because of spatial representation and location accessibility. Batura, Pasu, and Barpu glacier belong to Hunza sub-basin, the $59.2 \mathrm{~km}$ length makes Batura ranked $4^{\text {th }}$ on the eight longest glaciers in the middle-low latitude region, it has the maximum value of vertical height difference and was classified as a mustagh-type glacier for multiple branches nourished by large avalanches (Boerst, Winiger \& Bookhagen, 2013; Hewitt, 2011). Pasu, is adjacent to Batura, has retreated about $1.5 \mathrm{~km}$ since the end of the $19^{\text {th }}$ century, it is characterized by small end moraines that consist mostly of till in the form of hammocks and small parallel ridges (Owen \& Leicester, 1989). Barpu is lying in the southwestern part of the Karakoram range. Sachen and Chungphar glacier belong to the Astore sub-basin, Sachen is located on the eastern slope of Nanga Parbat massif nourished mostly by ice-fall avalanches, in contrast, Chungphar is situated on the southern foothills, and one tributary has shown a low retreat rate, which is characterized by extremely steep topography and vertical gradients. Gharko glacier belongs to UIB_D sub-basin. Figure 3 (b)-(c) exhibited the geomorphological feature on Barpu and Pasu glacier, we examined these glaciers were debris mantled as a consequence of abundant supply by rock avalanching process, with low ice velocities and no efficient system of debris removal (Shroder, Bishop, Copland \& Sloan, 2000).

GPR work was from August to October during 2016 to 2018, the surveying data were recorded with a distance ranging from 30 to $50 \mathrm{~m}$ on the glacier surface along with the transverse profiles, the coincided GPS with GPR measured locations and routes were depicted in Figure 3 (d)-(i) subplots respectively. We completed four transverse and three longitudinal profiles from the terminus to the upper reaches on Sachen glacier along with the central flowline and conducted six and five profiles on Barpu and Gharko glacier, respectively. Three transverse profiles in the tongue area of Batura, four profiles in the fissure zone of Pasu, and three profiles within a small elevation below $3000 \mathrm{~m}$ on Chungphar were finished. Totally, 26 GPR topographic profiles and 187 points, the ice thickness of the glacier boundary was assumed to be zero, including rock outcrops.

FIGURE 3 The GPR observation overview, (a) Location of six surveyed glaciers in the UIB sub-basins. (b)-(c) field working photography that displayed geomorphological features on Barpu and Pasu glacier. (d)-

(i) The GPR surveyed routes and points, the solid blue dots and black lines denote surveyed points and profiles, respectively

The discrimination of ice thickness mainly relies on the quality of the GPR data, Figure 4 has shown some representative raw radargrams. Hyperbola presented the englacial object signature, they have a complete and a sharp radar wave that we can distinguish the interface between ice and bedrock and correct the $d t$ -value on the GPR screen in the case of the noise. Any change in the dielectric constant of ice and rock shows a change in reflection, sometimes, the non-bed reflector occurred because of the entrained debris layer, vertical discontinuity, and meltwater in summer. The whole conducted points and calculated results were 
posted in the appendix information Table S1.

FIGURE 4 The representative GPR radargrams of six selected glaciers

\subsection{Optimized parametric schemes of GlabTop2}

GlabTop2 estimates were based on SRTM-C DEM that released in 2011, while GPR measurements were carried out from 2016 to 2018 . The estimated ice thickness and surveyed ones could not be compared directly because the ice surface changed during the past decades, nevertheless, ice bed erosion occurred over the geological time scale, and it was usually calculated on a centennial-scale even though in rapid tectonic regions. The glacier bed erosion rate generally ranges from 1 to over $10 \mathrm{~mm} \mathrm{yr}^{-1}$, the ice bed position was assumed to be relatively much more stable than the ice thickness calculated on the modern time scale (Koppes \& Montgomery, 2009).

The GlabTop2-modeled result is intensely dependent on the parameters of $\tau$ and $f$, especially for the upper limit on $\tau_{\max }$. It has been revealed the optimal $\tau$ - value of five glaciers in northwestern China was between 50 to $175 \mathrm{kPa}$, and the fluctuation interval is large ( $\mathrm{Li}, \mathrm{Ng}$, Li, Qin \& Cheng, 2012), $\tau=150 \mathrm{kPa}$ was commonly used in the Karakoram range (Frey et al., 2014).. Regarding the $f$-value, it represents the friction between ice body and valley sides, depending on the aspect ratio of glacier width and midpoints' depth along the flow line. Namely, when the measured half-width becomes wider or the midpoints' depth turns shallower, the $f$ -value will turn larger, vice versa. It was verified that the measured glaciers in HKKH ranges have narrow shape, the values of half-width were relatively small, accompanied with thicker ice depth on central flowline.

As presented in Figure 5, we compared the GPR-surveyed ice bed topography with GlabTop2-modeled results under nine parametric schemes, the $\tau$ max-value was processed ranging from 100 to $150 \mathrm{kPa}$ that increased by $20 \mathrm{kPa}$ and $30 \mathrm{kPa}$ gradually, coupled with the $f$-value ranging from 0.7 to 0.9 that increased by 0.1 grades. To assess the reliability of the GlabTop2 intuitively, three commonly used evaluation indexes were quoted, including the Root Mean Square Error (RMSE), Mean Deviation (MD), and Nash Sutcliffe Efficiency (NSE):

$$
\begin{aligned}
& \mathrm{RMSE}=\sqrt{\frac{1}{n} \sum_{i=1}^{n}\left(h_{o}-h_{m}\right)^{2}}(5) \\
& M D=\frac{1}{n} \sum_{i=1}^{n}\left(h_{o}-h_{m}\right)(6) \\
& N S E=1-\frac{\sum_{i=1}^{n}\left(h_{o}^{n}-h_{m}^{n}\right)^{2}}{\sum_{i=1}^{n}\left(h_{o}^{n}-h_{o}\right)^{2}}(7)
\end{aligned}
$$

where $h_{o}$ refers to the observed ice bed elevation; $h_{m}$ refers to the modeled one; $h_{m}$ refers to the mean value of observed results; and $n$ means the number of measured points, these variables in equations (5) to (7) are identical. GlabTop2 performs high quality and better credibility when NSE-value is close to 1, together with the smaller RMSE and MD-values. There is a concept that ice bed elevation was deduced by ice surface elevation minus ice thickness, the thicker of ice depth, the lower of the ice bed elevation, implying that these two variables made an inversely proportional relationship on magnitude. GlabTop2 overestimated the actual ice bed elevation compared to GPR-measured results when $\tau$-value became smaller and $f$-value turned higher, that means we underestimated the actual ice thickness. In contrast, GlabTop2 overestimated the actual ice thickness compared to the surveyed results when the $\tau$-value became higher and the $f$-value turned smaller.

From the perspective of individual glaciers, we processed GlabTop2 on three kinds of glaciers (small, medium, and large-sized). Fig 5 (a)-(c) presented the comparison results of Batura, Barpu, and Sachen glaciers that possessed considerable GPR- measured samples. Batura $\left(243.5 \mathrm{~km}^{2}\right)$ belongs to the large-sized glacier, its RMSE, MD, and NSE-values of the GlabTop2-modeled ice bed elevation versus the GPR-measured ones were coincided best when $\tau=150 \mathrm{kPa}$ and $f=0.8$, Barpu $\left(90.6 \mathrm{~km}^{2}\right)$ belongs to the medium-sized glacier, the values of these referral indicators performed best when $\tau=120 \mathrm{kPa}$ and $f=0.8$, while Sachen $\left(9.5 \mathrm{~km}^{2}\right)$ belongs to a small-sized glacier, GlabTop2 experiment was not very ideal for the NSE-values were close to 0.5 
even extremely negative, displaying a divergent condition, the simulated ice bed elevation versus surveyed results fit better when $\tau=150 \mathrm{kPa}$ and $f=0.8$, even the MD-value reached to $-1.64 \mathrm{~m}$. The number of observed GPR samples on Pasu, Gharko, and Chhungpar was relatively inadequate, thence they were not explained separately, they have been discussed entirely in Figure 5 (d).

If we choose an identical parametric scheme to apply on all glaciers that various in geometry and acreage, it is a high probability that all glaciers would not perform best under one certain scheme, a reasonable solution is to select the most comprehensive one. From the perspective of total GPR-surveyed points of six glaciers, the NSE-values of these nine parametric schemes were all greater than 90\%, the MD-values of all validation points were between negative and positive $50 \mathrm{~m}$, and the RMSE-values were below $80 \mathrm{~m}$. Amazing consistency appeared on GlabTop2-estimated ice bed elevation versus GPR-surveyed results, demonstrating that GlabTop2 performed effectively because it kept the small gap with our observed data. Among nine parametric schemes, we choose four scenarios that raced better with smaller RMSE ([?] $65 \mathrm{~m}$ ), MD-values ([?] $25 \mathrm{~m}$ ), and reasonable NSE-values ([?] 0.967 ), the first two, $\tau=150 \mathrm{kPa}$ and $f=0.8 \& 0.9$; the last two, $\tau=120 \mathrm{kPa}$ and $f=0.7 \& 0.8$. As demonstrated in Figure 6 , by comparing the profiles of the GPR-surveyed ice bed elevation versus GlabTop2-reconstructed results along with the transverse and vertical lines, it was discovered that two schemes had a relatively large gap when $\tau=150 \mathrm{kPa}$ and $f=0.8 \& 0.9$. Prominently, the simulated ice bed landform was much shallower when the $f$-value turns higher. However, these two simulated results were extremely close when $\tau=120 \mathrm{kPa}$ and $f=0.7 \& 0.8$, the $f$-value had substantially less effect on estimated results than $\tau$-value for the HKKH region. In summary, the surveyed ice bed morphology and estimated results were fit better on BaG_01, BaG_03, BpG_01, BpG_03, PaG_03, PaG_04, SaG_03, SaG_04, SaG_06, GhG_02, GhG_05, and ChG_03 profiles when $\tau=120 \mathrm{kPa}$, it has covered three kinds of sized glaciers.

FIGURE 5 A comparison between the GPR-measured ice bed elevation with the GlabTop2-estimated results on (a)-(c) various sized glaciers and (d) total samples under nine parametric schemes

FIGURE 6 A comparison between the GPR-surveyed ice bed elevation with the GlabTop2-simulated results along with the measuring profiles under four selected parametric schemes

In order to select the uniform parameters scheme, Figure 7 exhibited the ice reserves and average ice thickness reconstructed by GlabTop2, GlabTop, Volume and Topography Automation model (Volta), and IDW interpolated methods, the IDW results of Sachen and Barpu glacier relying on a considerable amount of GPR points. These three SIA models have the identical principle that just DEM and glacier outline needed. Among them, ice thickness is obtained along several manually digitized branch lines by GlabTop, and Volta is a python script installed in ArcGIS that generated centerline network automatically based on the GIS hydrological tool, distance, and geographic analysis. For small-sized glacier, Sachen, the ice volume and average ice thickness reconstructed by GlabTop2, GlabTop, and Volta were almost kept in the order of magnitude. Taking the IDW-calculated ice reserves $\left(0.8 \mathrm{~km}^{3}\right)$ and mean ice thickness $(89.9 \mathrm{~m})$ as the most precise reference due to its valuably, GlabTop2 preserved the most similar ice volume quantity $\left(1.0 \mathrm{~km}^{3}\right)$, mean ice thickness $(105.0 \mathrm{~m})$, and spatial distribution feature when $\tau=120 \mathrm{kPa}$ and $f=0.8$, the estimated results from GlabTop and Volta deviated far from the IDW-calculated results. It was demonstrated that the actual condition was agreed with the GlabTop2 simulation effect when $\tau=120 \mathrm{kPa}$. However, the model performed best when $\tau=150 \mathrm{kPa}$ in the previous comparison of ice bed topography plots, indicating that the $\tau$-value impacted the final calculated results weakly on a small-sized glacier, even can be ignored. The trustworthiness of the selected parameter scheme $(\tau=120 \mathrm{kPa})$ was proved, despite slight differences $(0.2$ $\mathrm{km}^{3}$ ). Moreover, the glacier branch lines generated by Volta were much more straightforward than GlabTop that extracted from the contour lines manually. For medium-sized glacier, Barpu, its IDW-calculated ice volume $\left(6.6 \mathrm{~km}^{3}\right)$ was less than GlabTop2 estimates $\left(7.3 \mathrm{~km}^{3}\right)$ slightly when $\tau=120 \mathrm{kPa}$ and $f=0.8$, but far away from the GlabTop simulated result $\left(7.8 \mathrm{~km}^{3}\right)$, clarifying that this parametric scheme was also suitable for the medium-scale glacier. As for large-sized glacier, Batura, the Volta modeled ice volume $\left(23.1 \mathrm{~km}^{3}\right)$ was close to GlabTop2 simulated result $\left(25.7 \mathrm{~km}^{3}\right)$ when $\tau=120 \mathrm{kPa}$ and $f=0.8$.

It was worth noting that the IDW results usually generated shallower mean ice thickness and less ice re- 
serves than physical models, overestimated phenomena occurred on models' application. The ice thickness distribution reconstructed by GlabTop2 looks more authentic because it has taken surface morphology of per glacial grid into account. GlabTop and Volta emerged relative ideal status because the thickest parts always posited on the centerlines. Moreover, the vast majority of glaciers in the HKKH chains are cramped and slender, a moderate $f$-value conforms to the reality. Ultimately, it is more suitable to choose the parametric scheme $(\tau=120 \mathrm{kPa}$ and $f=0.8)$ applied to the whole UIB region.

FIGURE 7 The comparison of the estimated ice thickness among GlabTop2 $(\tau=120 \mathrm{kPa}$ and $f=0.8)$, GlabTop, Volta models, and IDW interpolated results on three kinds of sized glaciers, the solid black points and lines represented the GPR points and flowlines

\subsection{Spatial Distribution of the Simulated Ice Reserves}

We processed GlabTop2 depends on the verified optimal parametric scheme, three consistent boundary files were prepared, including glacier mask, SRTM-C DEM, and generated slope. The estimated ice thickness ranges distribution of the UIB sub-basins and the statistical glacier information were summarized in Figure $8 \& 9$, containing the total number, glacier area, basin area, average ice thickness, as well as ice reserves.

GlabTop2-estimated ice depth was varied from 0 to $488.1 \mathrm{~m}$, with an average value of $74.4 \mathrm{~m}$. The average ice thickness in the Karakoram range $(81.5 \mathrm{~m})$ was remarkably thicker than the Western Himalaya $(60.3 \mathrm{~m})$ and Hindukush range $(45.0 \mathrm{~m})$, it was lower than previous research slightly (Frey et al., 2014). The most abundant ice resources were focused on the Karakoram range that a semi dispersive glacier area concentrated massively, Hunza $\left(224.1 \mathrm{~km}^{3}\right)$, Shigar $\left(229.4 \mathrm{~km}^{3}\right)$, and Shyok $\left(585.6 \mathrm{~km}^{3}\right)$ high-altitude sub-catchments dominated an absolute advantage $(81.8 \%$ ). Less ice volume was stored in the Western Himalaya range, consisting of Astore $\left(15 \mathrm{~km}^{3}\right)$, Shiquanhe $\left(7.7 \mathrm{~km}^{3}\right)$ and Kharmong $\left(120.9 \mathrm{~km}^{3}\right)$ sub-basins that occupied $11.3 \%$ proportion, while the least quantity was found in the Hindukush range, it is composed of Gilgit $\left(50.3 \mathrm{~km}^{3}\right)$ and UIB_D (37.0 $\mathrm{km}^{3}$ ) sub-watershed that just accounted for a small proportion (6.9\%). Undoubtedly, from the viewpoint of geological structural units, significant spatial heterogeneity of glacier resources distribution exists in the UIB sub-basins, mainly was decided by the terrain and climatic condition. Ice thickness will become much shallower along the steep terrain at higher altitudes above $4000 \mathrm{~m}$, on the contrary, the thicker ice depth was distributed along the low-lying terrain below $4000 \mathrm{~m}$, most importantly, orographical precipitation provides abundant material supply. Therefore, the favorable environment for glacier development contained flat topography of the high-altitude region, integrated with sufficient materials accumulated, the terrain and climatic factors in the Karakoram range is much more beneficial for glacier emerging and preserving.

FIGURE 8 The GlabTop2-estimated ice thickness ranges distribution of the UIB sub-basins

FIGURE 9 The GlabTop2-estimated ice thickness ranges distribution and statistic glacier information of the UIB region

The heterogeneity distribution of water resources converted from ice volume (assuming a mean glacier density of $900 \mathrm{~kg} \mathrm{~m}^{-3}$ ), corresponding water level equivalents (WLE), and its available consumption time in the UIB sub-catchments were revealed in Figure 10 (a)-(c) successively. When discussing the converted water resources, its ranking and proportion feature was same as the ice reserves. Shyok $\left(527.1 \mathrm{~km}^{3}\right)$, Shigar $\left(206.4 \mathrm{~km}^{3}\right)$, and Hunza $\left(201.6 \mathrm{~km}^{3}\right)$ were in three top-ranked, can be regarded as the adequate region that possessed ample water resources more than $200 \mathrm{~km}^{3}$. The distribution of normal regions was dispersed relatively, including Kharmong $\left(108.8 \mathrm{~km}^{3}\right)$, Gilgit $\left(45.3 \mathrm{~km}^{3}\right)$, and UIB_D $\left(33.3 \mathrm{~km}^{3}\right)$ for they maintained the resemble quantity that less than $120 \mathrm{~km}^{3}$, in contrast, Astore $\left(13.3 \mathrm{~km}^{3}\right)$ and Shiquanhe $\left(6.9 \mathrm{~km}^{3}\right)$ were classified as the poor district that owned a few water resources ([?]20 $\left.\mathrm{km}^{3}\right)$.

We took sub-watersheds' area as the referenced divisor when assessing the WLE, its distribution feature and ranking gradation were different from the ice reserves. The maximum value of water resources per square kilometers emerged in Shigar $(29.3 \mathrm{~m})$ because of the minimal basin area, Shyok $(15.9 \mathrm{~m})$ and Hunza (14.7 $\mathrm{m})$ ranked behind inseparable, nevertheless, the WLE-value of Gilgit $(3.6 \mathrm{~m})$, Astore $(3.3 \mathrm{~m})$, Kharmong $(2.4$ 
$\mathrm{m})$, UIB_D $(1.2 \mathrm{~m})$, and Shiquanhe $(0.3 \mathrm{~m})$ are below $5 \mathrm{~m}$, the most extensive drainage area of Kharmong river causing the water scarcity occurred. Kharmong, overlapped with the Kashmir, is confronted with the dilemma of water resources, resulting in the territorial and resource dispute between Pakistan and India. Shiquanhe, located in the northwest TP, sorted bottom in all assessed units, it illustrated that short supply of water resources exists in the headwater region of the UIB mostly, guaranteeing water supply for the Shiquanhe sub-basin has become an urgent task between Pakistan and China. Not only upper reaches are basically in deficit condition, but also the water resources distribution of the downstream area is pessimistic. The UIB relies on water resources in the middle reaches that was comprised of Shigar, Hunza, and Shyok sub-catchments because they are keeping in a self-sufficient even surplus state.

\subsection{Spatial Homogeneous of the Hydrological Effect}

Ice reserves that stored in the UIB region is a significant-high-quality natural substantial reservoir for the downstream area of the Indus river, the importance of its hydrological effect is never overemphasized. According to the discharge data of hydrological stations in the UIB sub-basins that acquired from the Pakistan Water \& Power Development Authority (WAPDA), we analyzed the multi-year average discharge and interannual change trend by statistical unary linear regression as exhibited in Figure 10 (d)-(k). The annual discharge of Kharmong $\left(456.3 \mathrm{~m}^{3} \mathrm{~s}^{-1}\right)$, Shyok $\left(363.3 \mathrm{~m}^{3} \mathrm{~s}^{-1}\right)$, Hunza $\left(298.9 \mathrm{~m}^{3} \mathrm{~s}^{-1}\right)$, Gilgit $\left(284.6 \mathrm{~m}^{3} \mathrm{~s}^{-1}\right)$, and Shigar $\left(207.3 \mathrm{~m}^{3} \mathrm{~s}^{-1}\right)$ were quite higher than Astore $\left(143.3 \mathrm{~m}^{3} \mathrm{~s}^{-1}\right)$ and Shiquanhe $\left(76.3 \mathrm{~m}^{3} \mathrm{~s}^{-1}\right)$ sub-basins.

FIGURE 10 The heterogeneity feature of (a) converted water resources, (b) water level equivalents, and (c) available consumption time of water resources of the UIB sub-basins without considering glacier process and other variables. (d)-(k) demonstrated the interannual change trends of discharge based on hydrological stations

The available consumption time of glacier resources in the UIB sub-basins various in magnitude noticeably, it was inconsistent with the ice reserves. An available consumption time of Shyok is $46.0 \mathrm{y}$, that is to say, the ice resources will be depleted within 46.0 y under ideal status, Shigar (31.6 y) and Hunza (21.4 y) will be depleted within $32.0 \mathrm{y}$. On the contrary, the available consumption time of Kharmong ( $7.6 \mathrm{y})$ and Gilgit $(5.0 \mathrm{y})$ sub-basins were less than $8.0 \mathrm{y}$, even the depleted time of Astore (3.0 y) and Shiquanhe (3.0 y) sub-catchments were less than $3.0 \mathrm{y}$, they have the high expending speed of water reserves. Outstandingly, Kharmong owns a small WLE-value, but it can supply $7.6 \mathrm{y}$ for the outlet of the tributary, indicating that its dependence on glacier melting is relatively lower than Gilgit, Astore, and Shiquanhe sub-basins. Precipitation variations influence the Astore river predominantly, a slight decrease in annual and summer precipitation was observed in the last 30 years (Farhan, Zhang, Ma, Guo \& Ma, 2015). Accompanied by the annual discharge increased slightly from 1980 to 2015 as revealed in Figure 10 (i), it was confirmed that Astore sub-watershed was facing the lack of precipitation replenishment and accelerated glacier melting meanwhile. A total of $1270 \mathrm{~km}^{3}$ ice volume, corresponding to $1143.7 \mathrm{~km}^{3}$ water resources, there was 2249.2 $\mathrm{m}^{3} \mathrm{~s}^{-1}$ discharge at the Besham hydrological station near the Taberla Dam annually, the converted water resources will be exhausted within $16.1 \mathrm{y}$ as runoff for the UIB outlet on average. The above explanation proves that the UIB will be up against water shortage in the future evenly, especially in the sub-watersheds that located in the upper reaches and downstream area.

\section{5 | Uncertainty Analysis}

We analyzed what extent uncertainties in the inputs of GlabTop2 by incrementally changing parameters $(\tau$ and $f$ ). Figure 11 (a)-(d) described the boxplots of estimated ice volume and average ice thickness under nine parametric schemes, Table 1 can be referred to as detailed counted results. Discussed by glacier scale, the largest error of ice volume emerged on the large-sized glacier, Batura, maximum ice volume was twice than the minimum result, and the median value was about $25.0 \mathrm{~km}^{3}$ that close to the result of the optimal parametric scheme aforementioned $(\tau=120 \mathrm{kPa}$ and $f=0.8)$. For medium-sized glacier, the median values of Barpu and Pasu glacier were not different from the optimal modeled results strongly, it should be noted 
that for a small-sized glacier, the parameters' influence on the final simulated result was minimal, almost negligible. Discussed by sub-basins, the largest uncertainty exists in Shyok, Shigar, Hunza, the median value of Shyok was less than $600 \mathrm{~km}^{3}$ approximately that meet the final estimated result from the optimal parametric scheme selected previously, testifying that our estimation has no excessive deviation. As for ice thickness, various sized glaciers and sub-basins were basically below $150 \mathrm{~m}$, the largest value occurred on Sachen glacier and Shigar sub-catchment, the IDW interpolated results of Barpu and Sachen were also fitted with the median values reconstructed by GlabTop2.

We defined "sensitivity" ( $\Delta V)$ as various in estimated ice thickness divided by unperturbed value, expressed as a percentage, the unperturbed value is the mean ice thickness deduced by the optimal parametric scheme $(\tau=120 \mathrm{kPa}$ and $f=0.8)$. Figure $11(\mathrm{e})$-(f) plots $(ə h / \partial f \& \eta / \tau) / \mathrm{h}$ for an input perturbation of $\tau=50$, $100,120,150 \mathrm{kPa}$ and $f=0.5,0.6,0.7,0.8,0.9,1$. In absolute terms, while a decrease of $20 \mathrm{kPa}$ in $\tau$ - value can reduce the estimated ice thickness by $20 \%$, and a $30 \mathrm{kPa}$ plus in $\tau$ - value increased simulates about $25 \%$. By comparison, a 0.1 rising the $f$-value reduced ice thickness by about $10 \%$, and a 0.1 dropped $f$-value increased $15 \%$ estimate, it was proved that the final estimates were less sensitive to the $f$-value calculated by half-width.

FIGURE 11 Boxplots of the GlabTop2-estimated (a)-(b) ice volume and (c)-(d) average ice thickness on six selected glaciers and UIB sub-basins, the green triangle donates the median value. The sensitivity analysis of estimates for an increase on the (e) $\tau$-value and (f) $f$-value

\section{5 | CONCLUSIONS}

In this paper, we verified the critical parameters of GlabTop2 through GPR-measured ice thickness on six typical glaciers of the UIB region, and accomplished GlabTop2 estimates with SRTM-C DEM and PGI as inputs, then deduced the spatial distribution characteristics of ice thickness and ice reserves in the UIB sub-basins, certain conclusions are as follows.

We compared the plots and profiles of GPR-surveyed ice bed elevation versus GlabTop2-simulated results under nine parametric schemes, selected the parametric scheme that owns appropriate RMSE, MD, and NSE-values, it was found that they were fit better on several profiles when $\tau=120 \mathrm{kPa}$. Moreover, the IDW interpolated results maintained the most similar ice thickness and ice volume quantity with GlabTop2 simulates when $\tau=120 \mathrm{kPa}$ and $f=0.8$ than GlabTop and Volta model, it is more realistic to choose this comprehensive scheme applied to vast amounts of various sized glaciers.

GlabTop2-modeled results indicated that ice thickness of the UIB sub-basins was varied from 0 to $488 \mathrm{~m}$, with an average value of $74.4 \mathrm{~m}$, the average ice thickness in the Karakoram range $(81.5 \mathrm{~m})$ was slightly thicker than Western Himalaya $(60.3 \mathrm{~m})$ and Hindukush $(45.0 \mathrm{~m})$, significant heterogeneity was existing. The most abundant ice reserves was focused on the Karakoram range, Shyok (46.1\%), Shigar (18.2\%), and Hunza (17.7\%) high-altitude sub-basins that dominated an absolute advantage. Less ice resources were stored in the Western Himalaya range that Astore (1.2\%), Shiquanhe $(0.6 \%)$ and Kharmong (9.5\%) subbasins included, the least quantity was found in the Hindukush range consists of Gilgit (3.9\%) and UIB_D $(2.9 \%)$ sub-watershed just accounted for a small proportion. Moreover, Shigar $(29.3 \mathrm{~m})$ possessed the most abundant water resources per square kilometers because of the limited basin area, Shyok (15.9 m) and Hunza $(14.7 \mathrm{~m})$ ranked behind inseparable, the WLE-values of Gilgit, Astore, Kharmong, and Astore sub-basins are all below $10 \mathrm{~m}$.

The available consumption time of the converted water resources of the UIB sub-basins various in magnitude, the ice resources of Shyok will be depleted within $46.0 \mathrm{y}$ without considering the glacier process and other variables, then Shigar (31.6 y) and Hunza (21.4 y) ranked behind. In contrast, Kharmong (7.6 y) and Gilgit $(5.0 \mathrm{y})$ will be depleted within less than $8.0 \mathrm{y}$, outstandingly, the exhausting time of Astore $(2.9 \mathrm{y})$ and Shiquanhe $(2.9 \mathrm{y})$ were less than $3.0 \mathrm{y}$, Astore is confronting with the lack of precipitation replenishment and accelerated glacier melting, the water resources of headwater region, The water resource of Shiquanhe 
subbasin is in short supply mostly. Not only the water supply of the upper reaches is basically in deficit condition, but also the downstream area is not optimistic, the UIB will be up against water shortage evenly in the future, especially for the Shiquanhe and Astore sub-basins. Nevertheless, the UIB depends on the ice melting of the middle reaches (Shigar, Shyok, and Hunza) because they are staying in a self-sufficient even surplus state, A total of $1269.7 \mathrm{~km}^{3}$ ice reserves was equivalent to $1142.7 \mathrm{~km}^{3}$ water resources, it can supply at least $16.1 \mathrm{y}$ for the Besham hydrological station as runoff.

With global warming and rapid glacier shrinkage in recent decades, accurate ice volume estimates in this hot region will receive unprecedented attention. The integration of GPR, GPS, GIS, and GlabTop2 will make the glacial field working more dynamic and predictive, our estimates make the audience have a clear cognition of the magnitude and distribution characteristic of ice reserves in the UIB sub-basins. Synthesizing knowledge of the ice thickness and ice reserves provides critical information for water resources management and regional glacial scientific research, it is also essential for several other fields of glaciology, including hydrological effect, regional climate modeling, and assessment of glacier hazards.

\section{ACKNOWLEDGMENTS}

We appreciate Dr. Holger Frey and Dr. Horst Machguth for providing the GlabTop2 model and the research followers of SUPARCO, PMD, and WAPDA that supporting Pakistan glacier inventory and hydrological data. We also thank the anonymous reviewers for their careful reading and insightful suggestions.

\section{DATA AVAILABILITY STATEMENT}

The data that support the findings of this study are openly available in National Tibetan Plateau Data Center athttps://data.tpdc.ac.cn/en/data/4a5f1e51-deb7-4ad2-bff9-a63erba724f9/.

\section{REFERENCES}

Azam, M. F., Wagnon, P., Ramanathan, A., et al. (2012). From balance to imbalance: a shift in the dynamic behaviour of Chhota Shigri glacier, western Himalaya, India. Journal of Glaciology,58 (208), 315324. http://doi.org/10.3189/2012JoG11J123

Bahr, D. B., Pfeffer, W. T. \& Kaser, G. (2015). A review of volume-area scaling of glaciers. Reviews of Geophysics, 53 (1),95-140. https://doi.org/10.1002/2014RG000470

Bajracharya, S. R. \& Basanta, S. (2011). The status of glaciers in the Hindu Kush-Himalayan region . Kathmandu, Nepal.: International Centre for Integrated Mountain Development.

BGIG. (1979). The Batura glacier in the Karakoram mountains and its variations. Scientia Sinica, 22 (8), 958-974. https://doi.org/10.1360/ya1979-22-8-958

Bishop, M., Bush, A., Copland, L., et al. (2010). Climate change and mountain topographic evolution in the Central Karakoram, Pakistan.Annals of the Association of American Geographers, 100 (4), 772-793. http://doi.org/10.1080/00045608.2010.500521

Boerst, U., Winiger, M. \& Bookhagen, B. (2013).Batura-Glacier-mass balance and 'Karakoram Anomaly' (Upper Hunza, Karakoram) .Paper Presented at 95th American Geophysical Union, San Francisco, America.

Bolch, T., Kulkarni, A., Kaab, A., et al. (2012). The State and Fate of Himalayan Glaciers. Science, 336, 310-314. http://doi.org/10.1126/science.1215828 
Chen, J. Y. \& Ohmura, A. (1990). Estimation of Alpine glacier water resources and their change since the 1870s. LAHS Publ,193, 127-135.

Cogley, G. (2012). Glaciology: No ice lost in the Karakoram.Nature Geoscience, 5 (5), 305-306. http://doi.org/10.1038/ngeo1456

Dahri, H., Ludwig, F., Moors, E., Ahmad, B., Khan, A. \& Kabat, P. (2016). An appraisal of precipitation distribution in the high-altitude catchments of the Indus basin. Science of the Total Environment,548-549, 289-306. http://doi.org/10.1016/j.scitotenv.2016.01.001.

Farhan, S. B., Zhang, Y. S., Ma, Y. Z., Guo, Y. H. \& Ma, N. (2015). Hydrological regimes under the conjunction of westerly and monsoon climates: a case investigation in the Astore Basin, Northwestern Himalaya. Climate Dynamics, 44 (11-12), 3015-3032. http://doi.org/10.1007/s00382-014-2409-9

Farinotti, D. (2017). Cryospheric science: Asia's glacier changes. Nature Geoscience, 10, 1-2.

Farinotti, D., Brinkerhoff, D., Clarke, G., Fürst, J., Frey, H. \& Gantayat, P. (2017). How accurate are estimates of glacier ice thickness? Results from ITMIX, the Ice Thickness Models Intercomparison eXperiment. The Cryosphere, 11 (2), 949-970. http://doi.org/10.5194/tc-11-949-2017

Farinotti, D., Huss, M., Furst, J., et al. (2019). A consensus estimate for the ice thickness distribution of all glaciers on Earth.Nature Geoscience, 12 (3), 168-174. http://doi.org/10.1038/s41561-019-0300-3

Frey, H., Machguth, H., Huss, M., et al. (2014). Estimating the volume of glaciers in the HimalayanKarakoram region using different methods. The Cryosphere, 8 (6), 2313-2333. http://doi.org/10.5194/tc8-2313-2014

Fürst, J. J., Gillet, C., Fabien, Benham, T., et al. (2017). Application of a two-step approach for mapping ice thickness to various glacier types on Svalbard. The Cryosphere, 11, 2003-2032. http://doi.org/10.5194/tc11-2003-2017

Gärtner, R., Naegeli, K., Huss, M., Knecht, T., Machguth, H. \& Zemp, M. (2014). A database of worldwide glacier thickness observations.Global and Planetary Change, 122, 330-344. http://doi.org/10.1016/j.gloplacha.2014.09.003

Garzonio, R., Di Mauro, B., Strigaro, D., et al. (2018). Mapping the suitability for ice-core drilling of glaciers in the European Alps and the Asian High Mountains. Journal of Glaciology,64 (243), 12-26. http://doi.org/10.1017/jog.2017.75

Grinsted, A. (2013). An estimate of global glacier volume. The Cryosphere, 7 (1), 141-151. http://doi.org/10.5194/tc-7-141-2013

Guo, W., Liu, S., Xu, J., et al. (2015). The second Chinese glacier inventory: data, methods and results. Journal of Glaciology, 61 (226), 357-372.

Haeberli, W. \& Hölzle, M. (1995). Application of inventory data for estimating characteristics of and regional climate-change effects on mountain glaciers: a pilot study with the European Alps. Annals of Glaciology, 21 (1), 206-212. http://doi.org/10.3189/S0260305500015834

Hewitt, K. (1998). Glaciers receive a surge of attention in the Karakoram Himalaya. EOS, 79 (8), 97-106. https://doi.org/10.1029/98EO00071

Hewitt, K. (2011). Glacier Change, Concentration, and Elevation Effects in the Karakoram Himalaya, Upper Indus Basin. Mountain Research and Development, 31 (3), 188-200. http://doi.org/10.1659/mrd-journal-d$11-00020.1$

Hewitt, K. (2016). Karakoram in transition Culture, Development, and Ecology in the Hunza Valley-Chapter5 Glaciers of the Hunza Basin and related Features . 49-72, Oxford, UK: Oxford University Press. 
Huss, M. \& Farinotti, D. (2012). Distributed ice thickness and volume of all glaciers around the globe. Journal of Geophysical Research: Earth Surface, 117 (F4), 1-10. http://doi.org/10.1029/2012JF002523

Immerzeel, W. W., Ludovicus, P. H. \& Bierkens, M. F. P. (2010). Climate change will affect the Asian water towers. Science, 328,1382-1385. http://doi.org/10.1126/science.1183188

Immerzeel, W. W., Lutz, A. F., Andrade, M., et al. (2019). Importance and vulnerability of the world's water towers. Nature,577, 364-369. https://doi.org/10.1038/s41586-019-1822-y

Khan, A., Naz, B. \& Bowling, L. (2015). Separating snow, clean and debris covered ice in the Upper Indus Basin, Hindukush-Karakoram-Himalayas using Landsat images between 1998 and 2002. Journal of Hydrology, 521, 46-64. http://doi.org/10.1016/j.jhydrol.2014.11.048

Khan, A., Richards, K. S., Parker, G. T., McRobie, A. \& Mukhopadhyay, B. (2014). How large is the Upper Indus Basin? The pitfalls of auto-delineation using DEMs. Journal of Hydrology, 509,442-453. http://doi.org/10.1016/j.jhydrol.2013.11.028

Koppes, M. N. \& Montgomery, D. R. (2009). The relative efficacy of fluvial and glacial erosion over modern to orogenic timescales.Nature Geoscience, 2 (9), 644-647. http://doi.org/10.1038/NGEO616

Li, H. L., Ng, F., Li, Z. Q., Qin, D. H. \& Cheng, G. D. (2012). An extended "perfect-plasticity" method for estimating ice thickness along the flow line of mountain glaciers. Journal of Geophysical Research: Earth Surface, 117 (F1), 1-11. http://doi.org/10.1029/2011jf002104

Linsbauer, A., Frey, H., Haeberli, W., Machguth, H., Azam, M. \& Allen, S. (2016). Modelling glacier-bed overdeepenings and possible future lakes for the glaciers in the Himalaya-Karakoram region. Annals of Glaciology, 57 (71), 119-130. 10.3189/2016AoG71A627

Liu, S. Y. (2012). Glacier Observation and Research Methods . Beijing, CN: Science Press.

Liu, S. Y., Shen, Y. P., Sun, W. K. \& Li, G. (2002). Glacier Variation since the Maximum of the Little Ice Age in the Western Qilian Mountains, Northwest China. Journal of Glaciology and Geocryology,24 (3), 227-233. http://doi.org/1000-0240(2002)03-0227-07

Lutz, A. F., Immerzeel, W. W., Shrestha, A. B. \& Bierkens, M. F. (2014). Consistent increase in High Asia's runoff due to increasing glacier melt and precipitation. Nature Climate Change,4 (7), 587-592. http://doi.org/10.1038/NCLIMATE2237

Marussi, A. (1964). Geophysics of The Karakorum . Florence Italy: E J Brill Leiden Press.

Maussion, F., Butenko, A., Champollion, N., et al. (2019). The Open Global Glacier Model (OGGM) v1. 1. Geoscientific Model Development, 12 (3), 909-931. https://doi.org/10.5194/gmd-2018-9

Nye, J. (1952). A Comparison Between the Theoretical and the Measured Long Profile of the Unteraar Glacier. Journal of Glaciology,2 (12), 103-107. http://doi.org/10.1017/s0022143000034006

Owen, L. \& Leicester, D. (1989). The Karakoram glacial depositional system. Zeitschrift für Geomorphologie, 76 (Suppl.),33-73.

Palazzi, E., Hardenberg, J. V. \& Provenzale, A. (2013). Precipitation in the Hindu-Kush Karakoram Himalaya: Observations and future scenarios.Journal of Geophysical Research: Atmospheres,118 (1), 85-100. http://doi.org/10.1029/2012jd018697

Paterson, W. S. B. (1970). The sliding velocity of Athabasca glacier, Canada. Journal of Glaciology, 9 (55), 55-63. http://doi.org/10.3189/S0022143000026794

Paterson, W. S. B. (1994). Physics of glaciers. 3rd edition. 480. New York: Elsevier Sci.

Pritchard, H. D. (2019). Asia's shrinking glaciers protect large populations from drought stress. Nature, 569, 649-654. https://doi.org/10.1038/s41586-019-1240-1 
Radić, V. \& Hock, R. (2011). Regionally differentiated contribution of mountain glaciers and ice caps to future sea-level rise. Nature Geoscience, 4 (2), 91-94. http://dx.doi.org/10.1038/ngeo1052

Radić, V. \& Hock, R. (2013). Glaciers in the Earth's Hydrological Cycle: Assessments of Glacier Mass and Runoff Changes on Global and Regional Scales. Surveys in Geophysics, 35 (3),813-837. http://doi.org/10.1007/s10712-013-9262-y

Shroder, J., Bishop, M., Copland, L. \& Sloan, V. F. (2000). Debris-covered glaciers and rock glaciers in the Nanga Parbat Himalaya, Pakistan. Geografiska Annaler: Series A, Physical Geography,82 (1), 17-31. http://doi.org/10.1111/j.04353676.2000.00108.x

$\mathrm{Su}$, Z., Ding, L. F. \& Liu, C. H. (1984). Estimation of glacier thickness and its reserves in Tianshan Mountains. Xinjiang Geography, 7 (2), 37-44. http://doi.org/10.13826/j.cnki.cn65-1103/x.1984.02.007

SUPARCO \& ITPCAS. (2015). Glacier Inventory of Pakistan . Karachi, PK: Pakistan Space \& Upper Atmosphere Research Commission.

Treydte, K. S., Schleser, G. H., Helle, G., et al. (2006). The twentieth century was the wettest period in northern Pakistan over the past millennium. Nature, 440, 1179-1182. http://doi.org/10.1038/nature04743

Vaughan, D., Comiso, J., Allison, I., et al. (2013). Climate Change 2013: The Physical Science Basis Observations of the Cryosphere.London, UK: Cambridge University Press.

Wang, M. H., Li, G., Shen, Y. \& Huang, M. H. (1996). Development of the Hot Water Jet of Model Glacier-II and its Application on the Hailuogou Glacier. Journal of Glaciology and Geocryology, 18 (Special Issue), 375-379.

Zhang, X. S., Chen, J. M. \& Wang, W. Y. (1996). Recent Variations of the Batura Glacier in the Karakoram Mountains. Journal of Glaciology and Geocryology, 18 (Special Issue), 33-45.

Zhang, X. S., Zhu, G. C., Qian, S., L., Chen, J. Y. \& Shen, Y. (1985). Radar Measuring Ice Thickness of NO.1 Glacier at the Source of Urumqi River, Tianshan. Journal of Glaciology and Geocryology,7 (2), 153-162. http://www.bcdt.ac.cn/CN/Y1985/V7/I2/153

\section{Hosted file}

Graphical Abstract_Submission.docx available at https://authorea.com/users/352482/articles/ 476720-quantifying-the-ice-storage-in-the-upper-indus-river-basin-with-the-groundpenetrating-radar-measurements-and-glacier-bed-topography-version-2-modeling
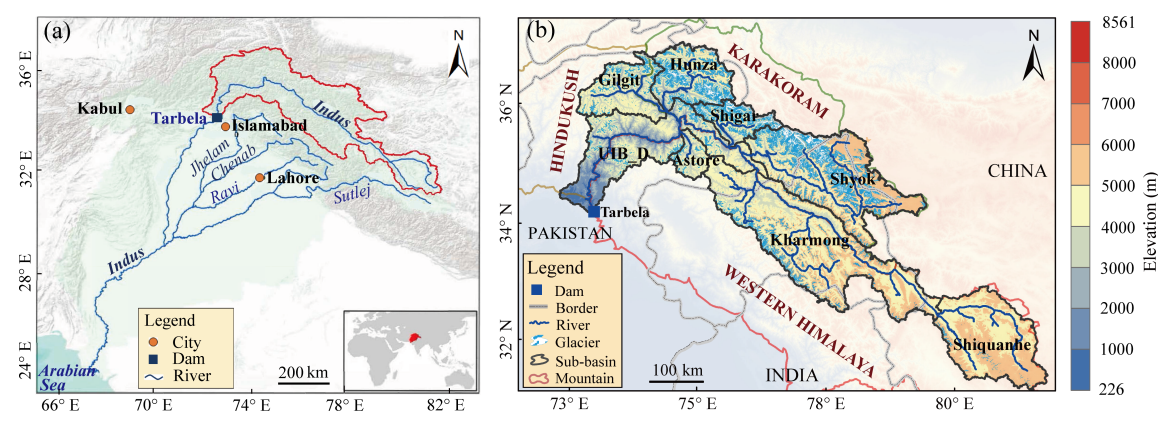

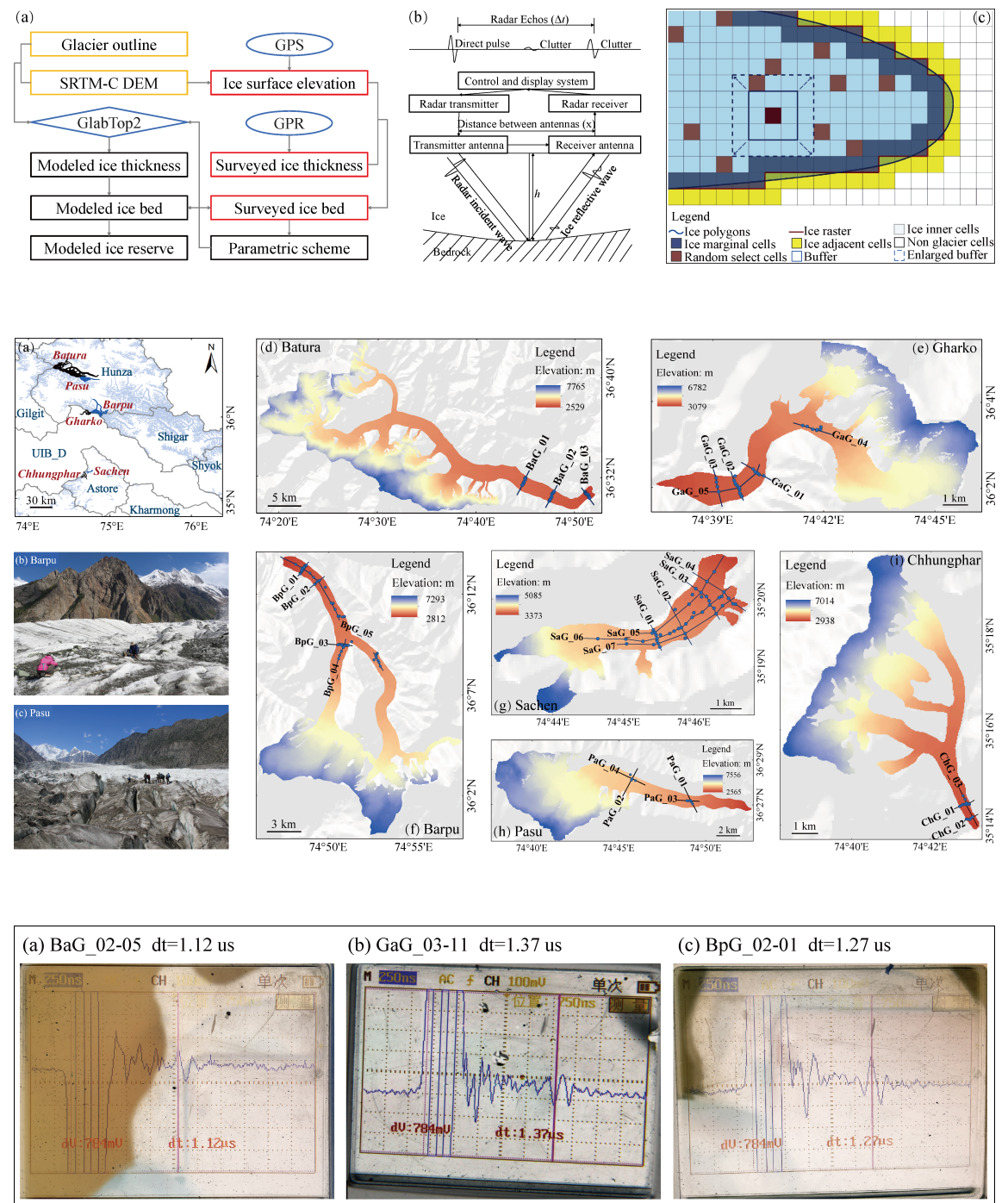

(b) GaG_03-11 dt=1.37 us

(c) BpG_02-01 dt=1.27 us
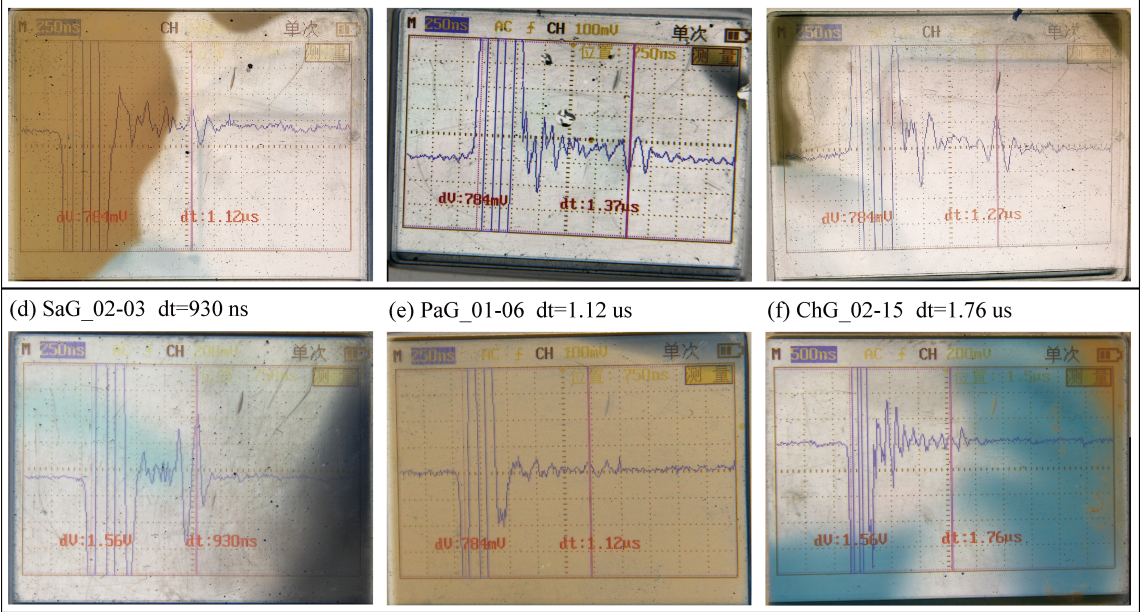

(e) PaG_01-06 dt=1.12 us

(f) ChG 02-15 dt=1.76 us
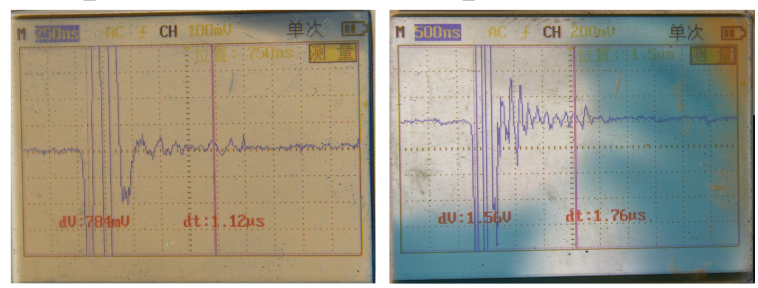
(a) Batura Large-sized glacier
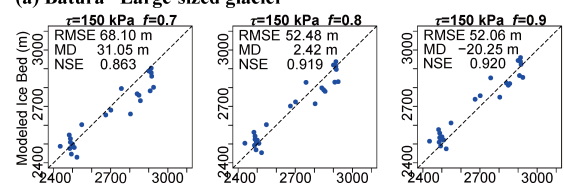

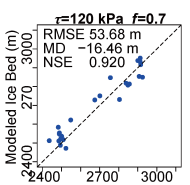

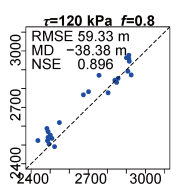

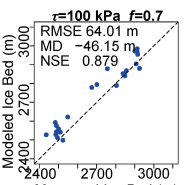

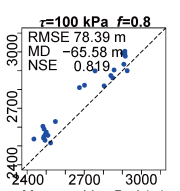

(c) Sachen Small-sized glacier
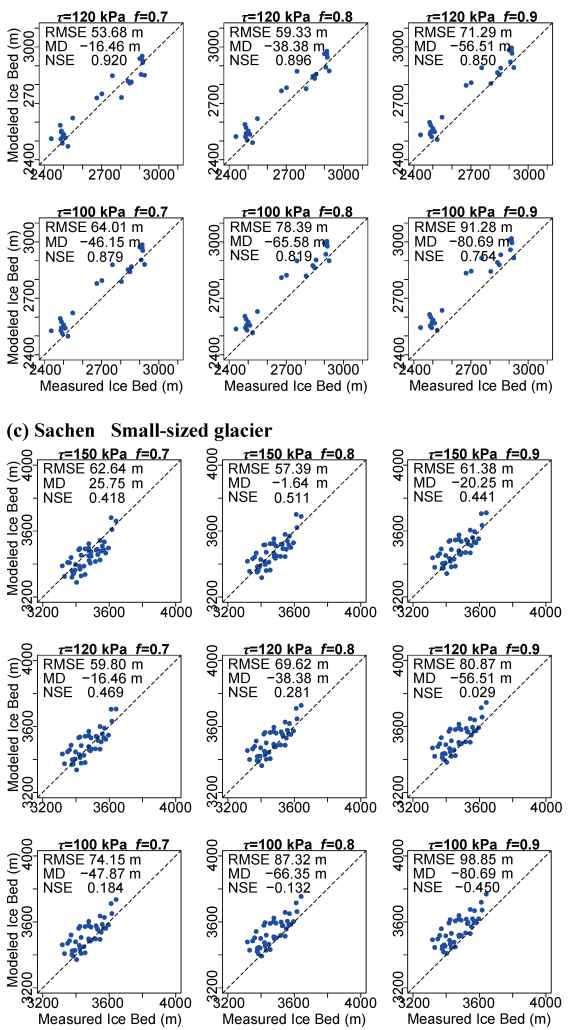

(b) Barpu Medium-sized glacier
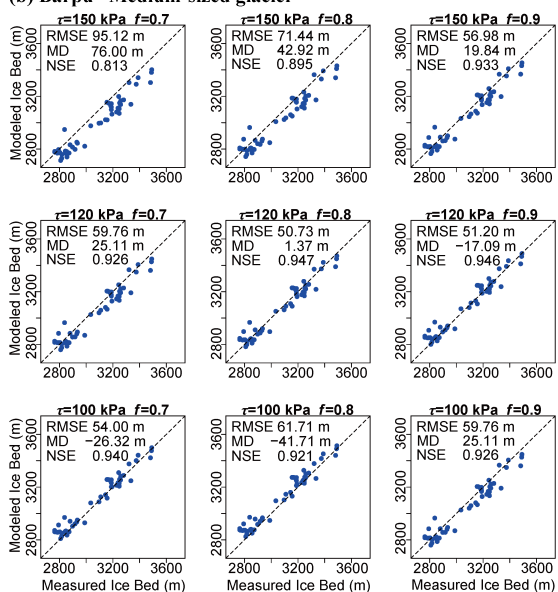

$\begin{array}{lll}2800 & 3200 \quad 3600\end{array}$

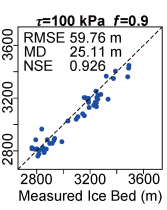

(d) Total Six glacier
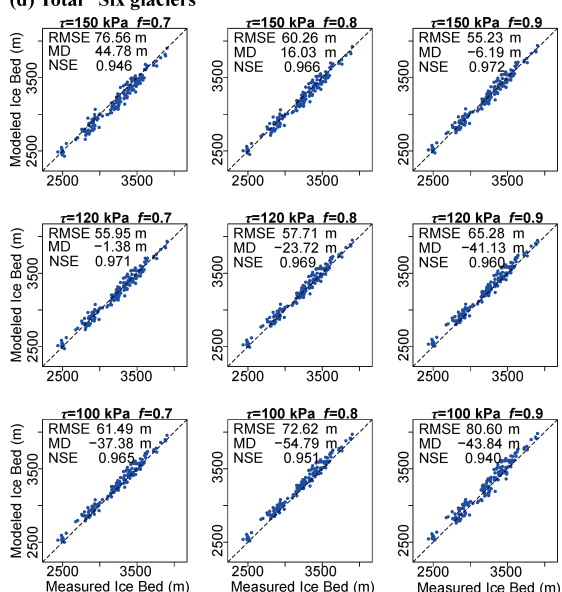

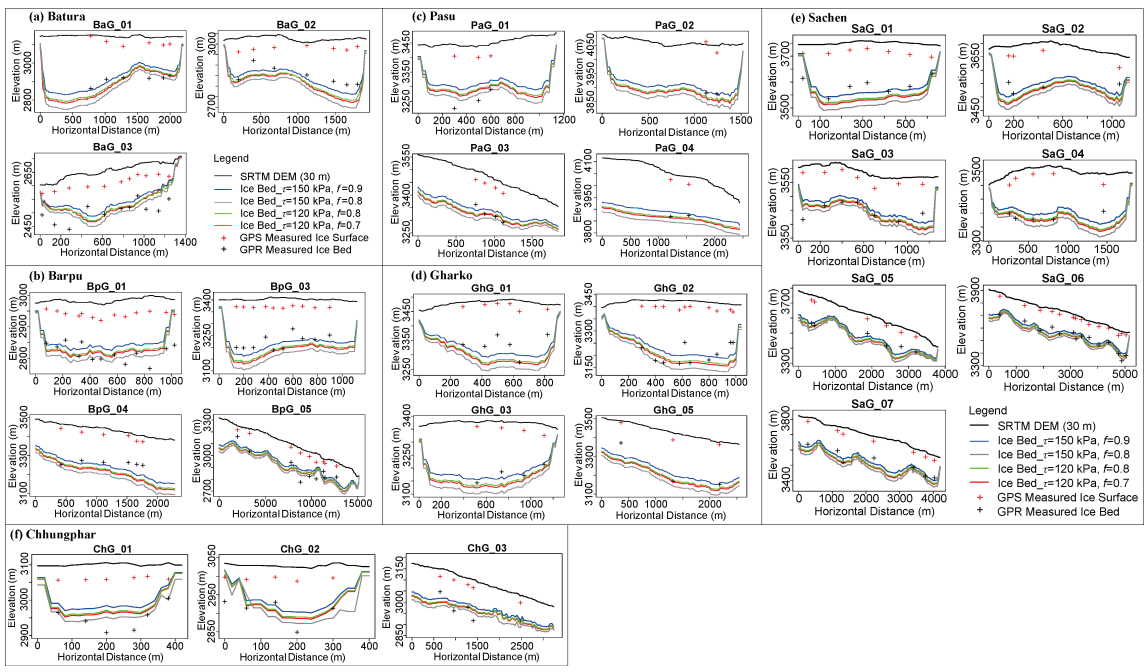



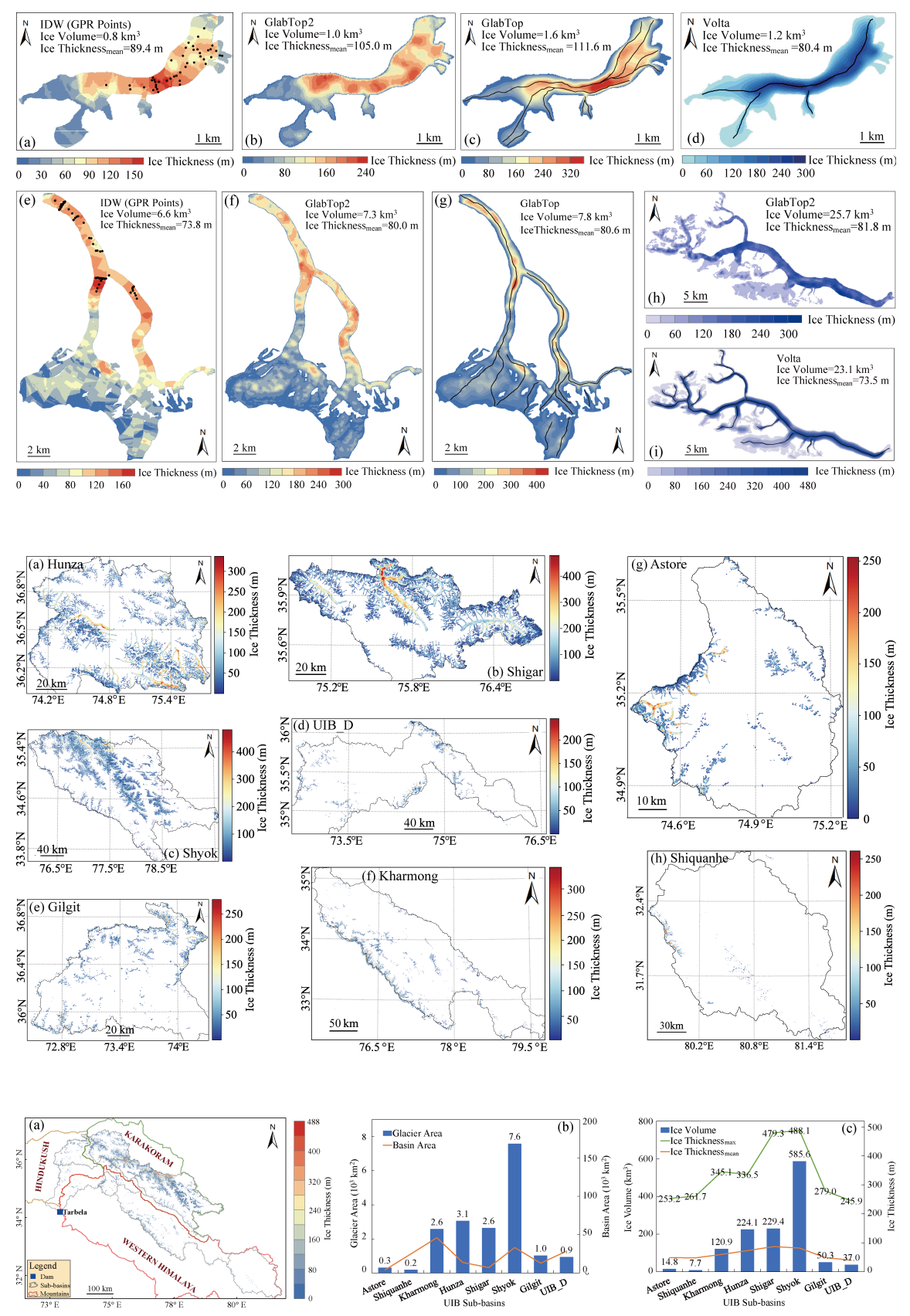

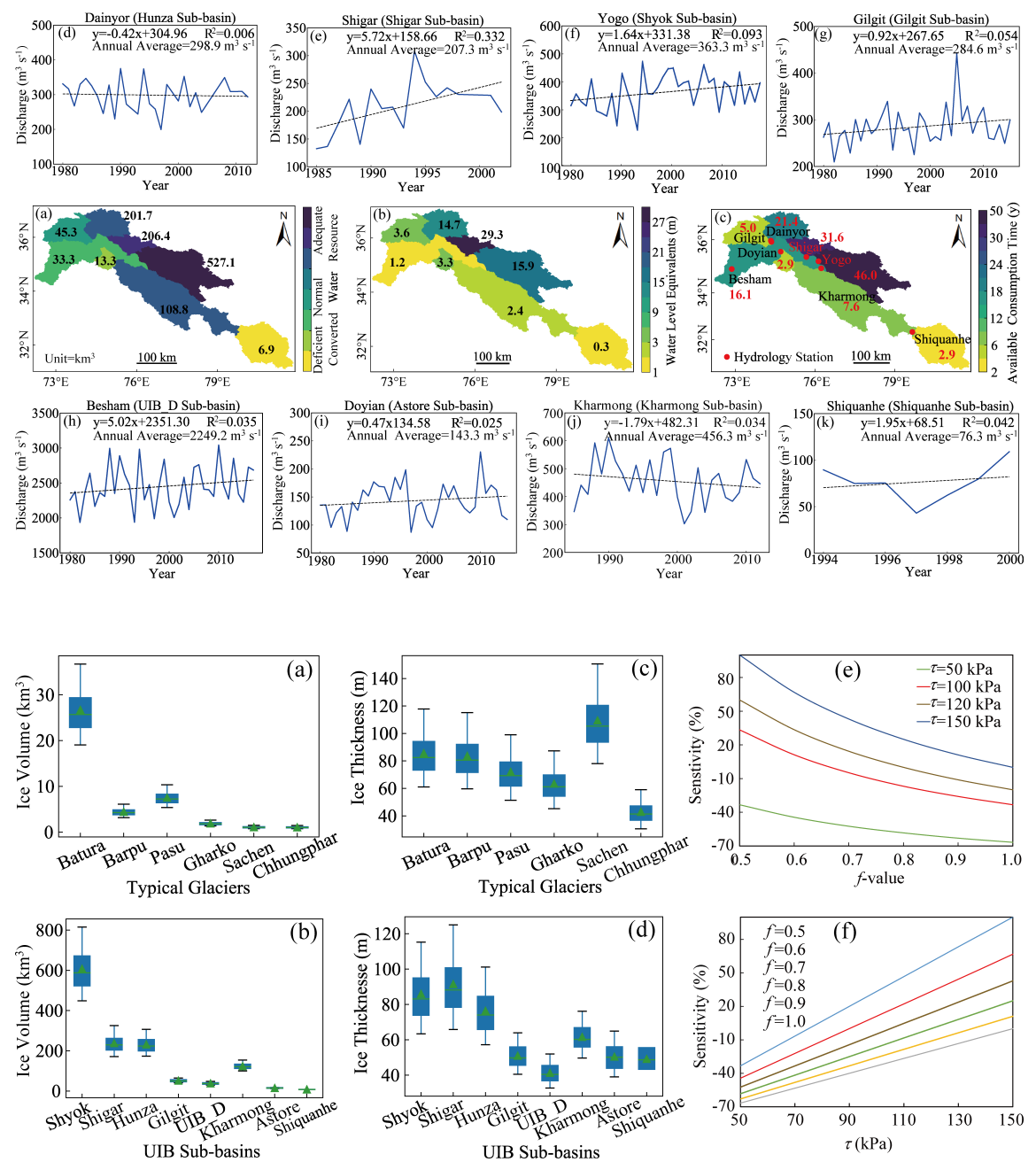

\section{Hosted file}

Table_Submission.docx available at https://authorea.com/users/352482/articles/476720quantifying-the-ice-storage-in-the-upper-indus-river-basin-with-the-ground-penetratingradar-measurements-and-glacier-bed-topography-version-2-modeling 